\title{
Comparative Analysis of Sinking Time Index and Water Stability of Different Inclusion Level of Cassava Flour and Brewer Yeast in a Test Diet
}

\author{
${ }^{1}$ Onada, Olawale Ahmed and ${ }^{2}$ Ogunola, Oluniyi Solomon \\ ${ }^{1}$ University of Ibadan, Ibadan, Nigeria \\ ${ }^{2}$ University of Bremen, Bremen, Germany
}

\begin{abstract}
The ability of fish feed to maintain its nutritional content for considerable period of time in pond water has become an important aspect of aquaculture. Several feed binder, mostly starch with other ingredient capable of creating air trap within the pellet of formulated feed has been used to improve the integrity of fish feed in water. The presence of the above characteristics in cassava flour and brewer yeast inform their selection for this experiment. This research, therefore, compares the effect of different percentage inclusion of cassava flour and brewer yeast on fish feed stability and sinking time index of a test diet. Pearson square method was used to formulate a $40 \%$ crude protein diet using fish meal, soyabean meal, groundnut cake, rice bran, maize and brewer dry grain. Cassava and yeast were included at 5, 10, 15, 20 and 25\% level and represented as C1, C2, C3, C4, C5 for cassava and Y5, Y4, Y3, Y2 and Y1 for yeast, respectively. The treatments were represented as C1Y5, C2Y4, C3Y3, C4Y2, C5Y1. Floatation tests and water stability test were conducted to determine floatation and the level of disintegration of the test diet per time, respectively. All data were analyzed using Analysis of Variance (ANOVA) followed by Fisher's Least Square Difference (LSD) at 5\% level of significance. The result of the experiment revealed significant different across the floatability of the test diet. The diet (C1Y5) had the best floating time index while the diet (C5Y1) had the least floatability performance. Water Stability shows diet (C5Y1) gave the best water stability percentage while (C1Y5) gave the least water stability percentage. The result of the experiment shows that brewer yeast is a very good floating agent and can support floatation of feed in water for more than $25 \mathrm{~min}$, while cassava flour has shown itself as a capable candidate for prolonging the stability of aqua feed in water. Further research can be conducted in the direction that will determine the percentage inclusion of a floating agent and a binder for maximum result of floatation and water stability determination.
\end{abstract}

Key words: Fish feed, feed binder, aquaculture, treatments, characteristics, experiment

\section{INTRODUCTION}

The success of fish farming business depends largely on the provision of low cost and good quality fish feed that can guarantee optimum feed conversion ratio. Presently, aquaculture production still frequently experiences low feed conversion efficiency which is mostly linked to feed wastage (Devenport, 2003). In a bid to produce good quality feed that will give the best feed conversion efficiency and reduce wastage, scientist have resolved to the production of feed with high nutritional value (Barrows et al., 2008) and maximum water stability and digestibility (Hansen and Storebakken, 2007; Booth et al., 2000; Bahurmiz and Ng, 2007) through the use of starch to bind nutrient components of feed together. Starch is an important component of fish feed, it serves the purpose of binding the ingredients in order to form a durable, floating and water stablepellet (Obi et al., 2011). In Nigeria, floating feed is in greater demand than sinking pellets, this is because it offers the opportunity for the farmer to observe feeding activityand satiation point of fish thereby discouraging overfeeding and feed wastage. Floating feed also exhibits superior characteristics such as greater water stability, digestibility, water protection, zero water pollution and zero wastage of raw materials (Almaraaj, 2015).

Unfortunately, only calculatedchoice of ingredient combination and starch component's will give the desired result of floatation and binding quality of the feed (Strahm and Plattner, 2001). Therefore, it is important tocombine ingredients that will give low bulk density and high buoyancy pelleted feed (Obi et al., 2011). In order to produce feed with these characteristics, it will require the inclusion of good quality feed binder which is normally starchy feed material like cassava tuber starch, maize flour starch ormillet flour starch among others (Solomon et al., 2011) in combination with other feed materials that have the characteristics of trapping air within pellet of the formulated feed such as yeast, duckweed, honeycomb and melon shell (Obi et al., 2011). The presence of the above characteristics in cassava flour and brewer's dry grain as reported by Solomon et al.

Corresponding Author: Onada, Olawale Ahmed, University of Ibadan, Ibadan, Nigeria 
(2011) inform their selection for this experiment. This research, therefore, compares the effect of different percentage inclusion of cassava flour and brewer yeast on fish feed stability and sinking time index.

\section{MATERIALS AND METHODS}

Source and processing of feed materials: The feed materials used for the experiment (cassava flour, fish meal, maize, yeast, groundnut cake, soyabean meal, rice bran and brewer dry grain) were all sourced from a reputable feed milling industry at Akobo, Ibadan. All the feedstuffs were given appropriate processing and handling care to improve their digestibility and remove anti-nutritional factor. Soyabean, groundnut cake and fish meal will be processed as described by Solomon et al. (2011) while yellow maize, rice branand brewer yeast were prepared following the description of Gbadamosi et al. (2006). Dried cassava tuber was ground to powder after processing and sieved with a $0.2 \mathrm{~mm}$ sieved before use in the formulation of the diet.

Feed formulation: Pearson square method was used to formulate a $40 \%$ crude protein diet using fish meal (25\%), soyabean meal (15\%) and groundnut cake $(10 \%)$ as the protein ingredient in the mixture, while rice bran (8\%), maize $(10 \%)$ and brewer dry grain (7\%) was included in the diet. Cassava and yeast were each included at 0, 5, 10, 15, 20 and 25\% level and represented as C1, C2, C3, C4, C5 for cassava and Y5, Y4, Y3, Y2 and Y1 for yeast, respectively. The treatments were represented as C1Y5, C2Y4, C3Y3, C4Y2, C5Y1.

Production of pellet: All ingredients to be used were severally milled until a fine particle of $0.5 \mathrm{~mm}$ size was achieved. This is necessary in order to ensure a homogenous particle size for proper mixing and binding of the diets (Houlihan et al., 2008; Jauncey et al., 2007). The milled ingredients were weight-out using Tree KRS 502 scale $500 \times 0.01 \mathrm{~g}$ precision in respect to the percentage of composition in the formulation earlier calculated as shown in Table 1. Other additives including salt, lysine, methionine and premixes were also added after which they were mixed together using a mini mixer until a homogenous blend was obtained (Table 2). Hot water was used to prepare the ingredients into consistent dough and the pellets were produced using $4 \mathrm{~mm}$ die holes on an extruding machine yearmega model DGP 120.

\section{Experimental set up}

Floatation or buoyancy test: Glass aquaria of dimensions $54 \times 30 \times 27 \mathrm{~cm}$ were filled up to $3 / 4$ of its capacity $\left(32805 \mathrm{~cm}^{3}\right)$ with tap water in the Fisheries and Aquaculture Laboratory of the University of Ibadan, Nigeria. Floatation or buoyancy tests were carried out using glass aquaria triplicates for each treatment, hence, a total of 15 glass aquaria were used for the study. Twenty pellets of each diet bound with different level of cassava and yeast as floater were dropped into the aquarium and observed for $25 \mathrm{~min}$ at $5 \mathrm{~min}$ interval. At the end of every observation (timing was made by a stop-watch), the number of pellets that were afloat were recorded accordingly. The mean numbers of the floating pellets were expressed as in Eq. 1:

$$
\text { Pellets afloat }(\%)=\frac{\text { Final No. of pellets afloat }}{\text { Initial No. of pellets afloat }} \times 100
$$

Water stability test: Water stability of each diet was measured for a period of 20, 40 and $60 \mathrm{~min}$. This was done by placing 10 pellets of each replicate into a nylon sieve materials of $1 \mathrm{~mm}$ mesh size, tied with a string and inserted into an aquarium containing pond water. At the end of every test time, one of the samples for each

Table 1: Gross composition of diet

\begin{tabular}{llllll}
\hline Feed materials & -- & - & - & & \\
\hline Fishmeal & 25 & 25 & 25 & 25 & 25 \\
Soyabean meal & 15 & 15 & 15 & 15 & 15 \\
Groundnut cake & 10 & 10 & 10 & 10 & 10 \\
Rice bran & 8 & 8 & 8 & 8 & 8 \\
Maize & 10 & 10 & 10 & 10 & 10 \\
BDG & 7 & 7 & 7 & 7 & 7 \\
Cassava & 5 & 10 & 15 & 20 & 25 \\
Yeast & 25 & 20 & 15 & 10 & 5 \\
Total & 100 & 100 & 100 & 100 & 100 \\
\hline
\end{tabular}

Table 2: Proximate composition of ingredient

\begin{tabular}{llllllll}
\hline Ingredient & M & CP & CL & CF & Ash & NFE & ME \\
\hline Rice bran & 1.5 & 12.19 & 1.0 & 11.4 & 2.0 & 72.30 & 2921 \\
Cassava flour & 0.8 & 10.58 & 0.6 & 13.1 & 1.0 & 70.32 & 2985 \\
Soyabean meal & 1.5 & 44.60 & 7.0 & 6.5 & 6.0 & 33.40 & 2798 \\
Brewer's dry grain & 2.5 & 21.88 & 4.5 & 15.3 & 2.5 & 55.82 & 2507 \\
Maize & 9.5 & 10.34 & 4.0 & 6.5 & 3.0 & 76.16 & 3554 \\
Fish meal & 3.5 & 68.50 & 10.2 & 2.5 & 8.0 & 10.9 & 2860 \\
Groundnut cake & 1.0 & 42.90 & 2.5 & 1.2 & 8.0 & 32.8 & 2864 \\
Yeast & 7.0 & 45.20 & 1.0 & 2.7 & 4.2 & 46.9 & 2842 \\
\hline
\end{tabular}

CP = Crude Protein (\%), CL = Crude Lipid (\%), NFE (\%), ME (kcal/kg) 
replicate was lifted slowly with the aid of the twine and allowed to drain for 3 min after which the contents were put on flat boards and sun-dried and weighed to obtain dry matter weight. The weight obtained here was the left over from the original weight after immersion due to disintegration for each test period, i.e., weight of whole pellets. The water stability was calculated as the percentage of the weight of retained (whole) pellets against the initial total sample dry weight as expressed in Eq. 2:

$$
\text { Water stability }(\%)=\frac{\text { Weight of retained whole pellets }}{\text { Initial total weight of pellets }} \times 100
$$

Data analysis: All data were analyzed using Analysis of Variance (ANOVA) followed by Fisher's Least Square Difference (LSD) at 5\% level of significance.

\section{RESULTS AND DISCUSSION}

Proximate composition: The proximate composition of the test diet shows that the treatment C1Y5 and C5Y1 has the highest and lowest percentage of crude protein, respectively with the crude protein decreasing across the treatment with decreasing percentage inclusion of yeast and increasing percentage inclusion of cassava flour. This attribute can be directly linked to higher crude protein in yeast as compared to cassava flour; this is as tarried with the findings of (Eyo, 2005). Crude fibre also shows slight significance among the treatments with no significance between C1Y5 and C2Y4 (Table 3).

Floatation result: The result shows significant different across the floatability of the test diet. The diet (C1Y5) had the best floating time index while the diet (C5Y1) had the least floatability performance. Generally, floatability decreases progressively from C1Y5 to C5Y1. This is directly proportional to the decrease in percentage inclusion of yeast and increase in percentage inclusion of cassava flour in the test diet. This results is similar to the result recorded by Momoh et al. (2016) and Falayi and Sadiku. The diet, however had better floatation than the result recorded by Adeparusi and Famurewa (2011) when $40 \%$ CP diets were produced, possibly as a result of the inclusion of yeast in the experimental diet.

Water stability result: Water stability shows significant difference across the test diet with a mild difference at $20 \mathrm{~min}$. A sharp difference was recorded at 40 min period. Generally, diet (C5Y1) gave the best water stability percentage while (C1Y5) gave the least water stability percentage. This shows a positive trend of higher percentage stability with higher percentage cassava inclusion. The results on Table 4 and 5 also suggest that there might be a negative correlation between water absorption and water stability of the pellets-diets with the least water absorption were seen to have the greatest water stability and vice versa. Although, water stability reduced for all the diets after $60 \mathrm{~min}$, the general trend was still maintained.

Effiong et al. (2009), reported a water stability of 82.81\% for fish feed formulated using cassava starch as binder after $1 \mathrm{~h}$ of exposure to water. This is however, higher than the $65.75 \%$ being reported in this research. This can be attributed to differences in the choice of treatment while this research included yeast; duckweed was used inthe research of Effiong et al. (2009), hence, accounting for the difference in water stability value.

Table 3: Proximate composition of diet

\begin{tabular}{llllll}
\hline Variables & C1Y5 & C2Y4 & C3Y3 & C4YY2 & C5Y1 \\
\hline Moisture (\%) & 4.4 & 4.6 & 4.7 & 4.6 & 4.8 \\
Crude protein & 43.0 & 41.2 & 39.9 & 39.1 & 38.6 \\
Crude fibre & 7.3 & 7.3 & 7.7 & 7.8 & 7.9 \\
Ether extract & 7.2 & 6.7 & 6.6 & 6.4 & 6.2 \\
*NFE & 38.1 & 40.2 & 41.1 & 42.2 & 42.7 \\
\hline
\end{tabular}

*Determined by subtraction from $100 \%$ of other parameters

Table 4: Floatation result (\%)

\begin{tabular}{|c|c|c|c|c|c|}
\hline Minutes & C1Y5 & $\mathrm{C} 2 \mathrm{Y} 4$ & C3Y3 & C4YY2 & C5Y1 \\
\hline 5 & $93.75 \pm 1.79^{\mathrm{a}}$ & $81.45 \pm 1.09^{b}$ & $67.5 \pm 1.12^{c}$ & $56.55 \pm 1.69^{d}$ & $49.75 \pm 1.09^{\mathrm{e}}$ \\
\hline 10 & $82.31 \pm 1.67^{a}$ & $67.45 \pm 2.14^{b}$ & $54.12 \pm 1.34^{c}$ & $37.14 \pm 1.34^{\mathrm{d}}$ & $25.42 \pm 2.40^{\mathrm{e}}$ \\
\hline 15 & $45.63 \pm 2.27^{\mathrm{a}}$ & $24.31 \pm 1.67^{\mathrm{b}}$ & $15.56 \pm 3.33^{c}$ & $0.00^{f}$ & $0.00^{f}$ \\
\hline 20 & $34.63 \pm 3.25^{\mathrm{a}}$ & $0.00^{f}$ & $0.00^{f}$ & $0.00^{f}$ & $0.00^{f}$ \\
\hline 25 & $22.34 \pm 2.24^{\mathrm{a}}$ & $0.00^{f}$ & $0.00^{f}$ & $0.00^{f}$ & $0.00^{f}$ \\
\hline
\end{tabular}

Means with same letter along the row are not significantly different according to Duncan multiple range test (p $=0.05)$

Table 5: Water stability (\%)

\begin{tabular}{|c|c|c|c|c|c|}
\hline Minutes & C1Y5 & C2Y4 & C3Y3 & $\mathrm{C} 4 \mathrm{Y} 2$ & C5Y1 \\
\hline 20 & $78.75 \pm 3.45^{\mathrm{a}}$ & $82.75 \pm 2.33^{b}$ & $87.5 \pm 1.64^{c}$ & $92.75 \pm 3.69^{d}$ & $96.75 \pm 1.59^{e}$ \\
\hline 40 & $54.75 \pm 2.14^{\mathrm{a}}$ & $61.75 \pm 1.60^{\mathrm{b}}$ & $66.61 \pm 1.57^{c}$ & $79.45 \pm 2.23^{\mathrm{d}}$ & $85.87 \pm 1.38^{\mathrm{e}}$ \\
\hline 60 & $24.75 \pm 1.79^{\mathrm{a}}$ & $33.75 \pm 1.09^{b}$ & $42.5 \pm 1.12^{\mathrm{c}}$ & $49.75 \pm 3.69^{d}$ & $65.75 \pm 1.09^{\mathrm{e}}$ \\
\hline
\end{tabular}

Means with same letter along the row are not significantly different according to Duncan multiple range test $(\mathrm{p}=0.05)$ 


\section{CONCLUSION}

The results of the experiment shows that brewer yeast is a very good floating agent and can support floatation of feed in water for more than 25 min. The result further indicates that cassava flour has shown itself as a capable candidate for prolonging the stability of aquaculture feed in water. Also, starch and brewer yeast also have beneficial nutritional advantage to the fish and are affordable. In summary, the different ingredients used and their percentage inclusion gives the resulting physical properties of the pellet. The quantity of starch used and inclusion of other materials that can create an air trap in the pellet will suggest the durability of the pellet, this is because starch gelatinizes and acts as a binding agent, the more starch present, the better the quality of the pellet.

\section{RECOMMENDATION}

Further research can be conducted in the direction that will determine the percentage inclusion of a floating agent and a binder for maximum result of floatation and water stability determination.

\section{REFERENCES}

Adeparusi, E.O. and J.A.V. Famurewa, 2011. Water temperature and surface coating effect on floatability, water absorption and thickness swelling of feed. J. Agric. Sci., 3: 254-254.

Almaraaj, S., 2015. Extruded floating fish feed, a boost for farmers. The Hindu Newspaper, Chennai, Tamil Nadu, India.

Bahurmiz, O.M. and W.K. Ng, 2007. Effects of dietary palm oil source on growth, tissue fatty acid composition and nutrient digestibility of red hybrid tilapia, Oreochromis sp., Raised from stocking to marketable size. Aquaculture, 262: 382-392.

Barrows, F.T., T.G. Gaylord, W.M. Sealey, L. Porter and C.E. Smith, 2008. The effect of vitamin premix in extruded plant-based and fish meal based diets on growth efficiency and health of rainbow trout (Oncorhynchus mykiss). Aquaculture, 283: 148-155.

Booth, M.A., G.L. Allan and R. Warner-Smith, 2000. Effects of grinding, steam conditioning and extrusion of a practical diet on digestibility and weight gain of silver perch, Bidyanus bidyanus. Aquaculture, 182: 287-299.
Devenport, J., 2003. Aquaculture. Blackwell Science Ltd., Oxford.

Effiong, B.N., A. Sanni and O.A. Sogbesan, 2009. Comparative studies on the binding potential and water stability of duckweed meal, corn starch and cassava starch. New York Sci. J., 2: 50-57.

Eyo, J.E., 2005. Effects of substituting soya bean meal for maggot meal on acceptability of diets, growth performance and cost benefits of diet fed to hybrid catfish-Heterobranchus bidorsalis (?) X Clarias gariepinus (?). J. Sci. Technol. Res., 4: 37-43.

Gbadamosi, O.K., E.A. Fasakin and O.T. Adebayo, 2006. Evaluation of dietary ascorbic acid supplementation in practical diets for African Catfish Clarias gariepinus (Burchell, 1822) fingerlings. J. Fish. Int., 1: 8-11.

Hansen, J.O. and T. Storebakken, 2007. Effects of dietary cellulose level on pellet quality and nutrient digestibilities in rainbow trout (Oncorhynchus mykiss). Aquaculture, 272: 458-465.

Houlihan, D., T. Boujard and M. Jobling, 2008. Food Intake in Fish. Blackwell Science Inc., Boston, USA., ISBN: 9780470999509, Pages: 448.

Jauncey, K., P.L. Sorensen and F. Areola, 2007. A short handbook-catfish feed for Nigeria (materials storage, handling, stock and quality control, ingredients, feed formulation, feed use/husbandry and technical aspects of feed manufacture). The CDE, Brussels, Belgium.

Momoh, A.T., M.Y. Abubakar and J.K. Ipinjolu, 2016. Effect of ingredients substitution on binding, water stability and floatation of farm-made fish feed. Int. J. Fish. Aquacult. Sci., 4: 92-97.

Obi, M.N., R.J. Kolo and A.M. Orire, 2011. The production of floating fish feed using melon shell as a floating agent. Int. J. Sci. Nat., 2: 477-482.

Solomon, S.G., G.A. Ataguba and A. Abeje, 2011. Water stability and floatation test of fish pellets using local starch sources and yeast (Saccahromyces cerevisae). Int. J. Latest Trends Agric. Food Sci., 1: $1-5$.

Strahm, B. and B. Plattner, 2001. Put the right tools in your toolbox to ease aquafeed extrusion. Feed Manage., 52: 19-22. 